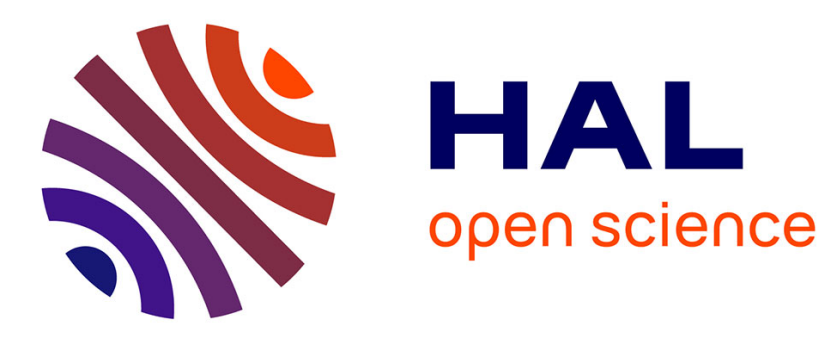

\title{
"Counting on the Group"
}

Matthieu Tixier, Myriam Lewkowicz

\section{To cite this version:}

Matthieu Tixier, Myriam Lewkowicz. "Counting on the Group". the 2016 CHI Conference, May 2016, Santa Clara, United States. pp.3545-3558, 10.1145/2858036.2858477 . hal-02310975

\section{HAL Id: hal-02310975 \\ https://hal-utt.archives-ouvertes.fr/hal-02310975}

Submitted on 14 Jun 2021

HAL is a multi-disciplinary open access archive for the deposit and dissemination of scientific research documents, whether they are published or not. The documents may come from teaching and research institutions in France or abroad, or from public or private research centers.
L'archive ouverte pluridisciplinaire $\mathbf{H A L}$, est destinée au dépôt et à la diffusion de documents scientifiques de niveau recherche, publiés ou non, émanant des établissements d'enseignement et de recherche français ou étrangers, des laboratoires publics ou privés. 
archives-ouvertes

\section{"Counting on the Group"}

Matthieu Tixier, Myriam Lewkowicz

\section{To cite this version:}

Matthieu Tixier, Myriam Lewkowicz. "Counting on the Group". the 2016 CHI Conference, May 2016, Santa Clara, France. pp.3545-3558, 10.1145/2858036.2858477 . hal-02310975

\section{HAL Id: hal-02310975 \\ https://hal-utt.archives-ouvertes.fr/hal-02310975}

Submitted on 14 Jun 2021

HAL is a multi-disciplinary open access archive for the deposit and dissemination of scientific research documents, whether they are published or not. The documents may come from teaching and research institutions in France or abroad, or from public or private research centers.
L'archive ouverte pluridisciplinaire HAL, est destinée au dépôt et à la diffusion de documents scientifiques de niveau recherche, publiés ou non, émanant des établissements d'enseignement et de recherche français ou étrangers, des laboratoires publics ou privés. 


\section{"Counting on the Group"}

\section{Reconciling Online and Offline Social Support among Older Informal Caregivers}

\author{
Matthieu Tixier \\ ICD, HETIC, Tech-CICO, \\ Troyes University of \\ Technology, \\ UMR 6281, CNRS, \\ Troyes, France \\ Matthieu.tixier@utt.fr
}

\author{
Myriam Lewkowicz \\ ICD, HETIC, Tech-CICO, \\ Troyes University of \\ Technology, \\ UMR 6281, CNRS, \\ Troyes, France \\ Myriam.lewkowicz@utt.fr
}

\begin{abstract}
Awareness of the huge amount of work faced by relatives in caring for a person suffering from a loss of autonomy has led to research focusing on ways to ease the burden on informal caregivers. Among them, services and devices aimed at providing social support and fighting the isolation that may be caused by the caregiving tasks appear important. However, little is known about the social support informal caregivers actually value and look for in practice. To fill this gap, we conducted a multi-sited study, focusing on older informal caregivers, because they are numerous and have lower experience with technology. Our study highlights that being part of a group is a key element in helping informal caregivers to feel that they are not alone, continue leisure activities, learn from others and sustain participation in organized activities. Through this understanding, we discuss design opportunities in a sociotechnical approach complementing online and offline social support.
\end{abstract}

\section{Author Keywords}

Informal caregivers; social support; respite services.

\section{ACM Classification Keywords}

H.5.2. User Interfaces: User-Centered Design; H.5.3. Group and Organization Interfaces: Computer-supported cooperative work, asynchronous interaction, web-based interaction. K4.1 Public Policy Issues: computer-related health issues

\begin{abstract}
INTRODUCTION
The current evolution of western healthcare systems related to demographic pressure has made institutions, society and research more and more aware of the importance of the informal care provided by relatives of persons suffering from severe conditions due to disease or ageing [17,61]. Informal elderly care is well established across the EU countries with its incidence ranging from 1-2\% for 20-39 year olds peaking at over $10 \%$ (approximately $5 \%$ for men) for over 50 year old women [68]. An analysis of the SHARE (Survey of Health, Ageing and Retirement in Europe) database [55] shows that partners/spouses are making up over $50 \%$ of persons providing personal care on a regular basis and children over $30 \%$. Actually, as the average age of parents has been increasing, fewer children less than 60 years old remain as prospective informal caregivers. In Europe, about $6 \%$ of the population aged 50 or over provide personal care for an older relative or family member. More than half of them (54\%) are in the 50-64 age group.
\end{abstract}

The observed economic benefit of informal care can be seen as an opportunity in the context of expense reduction $[35,57]$. However, the physical and psychological costs of assuming the role of an informal caregiver contradict such an analysis [32]. Indeed, caregiving is stressful [56], and caregivers are at risk for physical and emotional problems [53]. Indeed, depression is common among informal caregivers [38]; in France, caregivers of patients suffering from Alzheimer's disease (AD) suffer more from depression than the general population [65]. Providing support to informal caregivers appears then as a necessity and as an opportunity to think about how new approaches can complement institutionalized healthcare services. However, we are facing a situation in which no method for lowering their burden has clearly emerged from nursing, psychology, or other disciplines.

In this context, the Internet offers an alternative to traditional sources of support for informal caregivers, providing them a simple way to contact other caregivers for 
guidance and support $[9,12,22]$. But there are segments of caregivers less likely to utilize the Internet when assisting their sick relatives [12,49]. A recent study [39] conducted in the USA shows that caregivers' use of the Internet was significantly related to their age, education, income, primary caregiver status, caregiver strain, self-reported health, and information needs. This study also revealed that only about $11 \%$ of caregivers searched for information about caregiver support, which raises questions on whether caregivers recognize their own service needs and/or are aware of the availability of online caregiver support resources. This is especially true for older caregivers, who, in general, have harder time or lack of interest to use or adapt existing online solutions to help them with many daily tasks) [19]. In our research, we thus tackle especially the challenge of providing an accessible integrated social support platform to serve all relevant aspects of caregivers' social support needs $[30,46,59,67]$.

To understand the support and relief older informal caregivers are currently finding or looking for in their daily life, we have conducted a multi-sited field study, following different informal caregivers and the different types of support they are looking for or receiving in France. In this study, we have observed and collected different discourses regarding respite and social support, different types of support the informal caregivers benefit from, and the difficulties some older informal caregivers are facing to find or participate in these solutions. These findings gave us a source of inspiration for design perspectives of an online system that could provide new opportunities for older informal caregivers. In other words, we are interested in exploring how these online activities could complement offline activity. More precisely, we intend to participate in the on-going research question in the HCI and CSCW communities regarding the relationship between online and offline behavior and the implications for designing community-based ICTs $[21,25,33,37,42,62]$.

In the remainder of this article, we position our work, and then describe the settings of our multi-sited study and our findings. These findings and design opportunities are discussed following a socio-technical perspective [1], and we subsequently conclude.

\section{RELATED WORK}

Many studies have demonstrated the difficult role of being the caregiver of a sick relative and the struggle between maintaining a "normal" life and meeting caregiving obligations. In particular, [10] has illustrated that informal caregivers try to simultaneously maintain their physical, emotional, social and reflective selves. To face this situation, several projects have been dedicated to the design of health and well-being technologies.

Some of these technologies are ambient devices mainly tackling the emotional and physical selves of informal caregivers [18,23]. Other devices address the need for caregivers to watch over their sick relatives and are intended to diminish their stress $[15,16,46,58]$, while some technologies aim to lower the burden of interacting with a person with dementia, by offering memory assistance $[47,54]$ by helping the caregiver to maintain the conversation flow [27], or by using games [26].

Other studies have focused on the activities of informal caregivers, showing that, in a homecare situation, the professional work and responsibility that comes with it is shared among care recipients and informal caregivers. Some systems have then been designed in order to support this work ensemble comprised of professional actors as well as non-professional ones (the family members) $[5,6,7,11]$.

Finally, some research addresses the need for social support that informal caregivers face. Social support can be defined as a "multidimensional phenomenon that may be expressed through a number of different processes such as the provision of information and advice, help with caregiving, or communicating concern and compassion for the caregiver" [64]., or "an exchange of verbal and non-verbal messages, which transmit emotion or information in order to reduce the uncertainty or the stress of a person" [3]. In fact, apart from ambient devices to help them cope with their stress and watch over their relatives and applications to help them coordinate their care work with the professional care workers, informal caregivers also need a place to share their feelings. Indeed, the persons with whom they want to share these feelings are not their closest friends or parents but rather people who are also facing difficult situations and can understand. One of the reasons for this is the fear of being hurt by negative responses after sharing [73]. This type of exchange with people facing the same type of difficult situation can take place in existing face-toface solutions, such as support groups, but most caregivers lack the time to attend meetings, and sometimes it is even physically impossible for them to attend. This fact inspired the design of online social support solutions that integrate and provide easy access to existing social networks $[40,66,72]$. Another advantage of this type of online solution is the diminishment of substantial barriers to making the communication among caregivers as effective as they might like. These barriers can be related to gender and face management, such as the fear some men have regarding expressing their feelings in public [14] or the report of embarrassing situations (e.g., a woman being raped by her husband).

The exchange of social support through computer-mediated communication (CMC) for coping with a large range of difficult situations resulting from severe pathologies, loneliness and self-esteem problems has been described in a large corpus of CSCW and HCI studies, starting with online support groups $[4,13,29,31,34,36,70]$. Several research analyzed different phenomena, among which the commitment in online support group [69], the role of the Internet to gain recognition $[43,50]$, or the impact of different modalities $[28,41,60]$ on the online participation. 
If we focus on older adults, we can note that researches on the usage of CMC mainly investigated the accessibility of the Internet for older people and the impacts of age-related changes. Social support networks among older adults are significantly understudied [51,72]. However, studies on this subject have shown promising results $[2,49,52,71,74]$.

Our work follows and extends this latter category of research aiming to lower the burden of older informal caregivers and diminish their stress through social support. We are interested in understanding the different sources of support and respite older informal caregivers currently benefit from and value, with the idea of facilitating the transition between online and offline support.

Indeed, previous work has demonstrated that in-person community meetings and online communication are both important to increase social capital and collective efficacy, and how technologies can supplement established in-person meetings, not replace them [21]. In this study conducted in a neighborhood [21], the authors observed that the two modes of communication are very much intertwined: the residents gain information from online discussions and share it during the meetings (and vice versa). This result complements a study of a college campus acknowledging the movement between online and offline behavior that both accommodates existing relationships and supports new ones [20]. A recent study of civic crowdfunding [62] has gone deeper in studying this complementarity and has identified the two core roles of online activity for offline communities: "online as a virtual "discussion board" and information aggregator, and online as a place for coordination of offline activity." The authors insist on the importance of not excluding online and offline information and suggest that, on one hand, an offline community should be made aware of the range of online options available and provide incentives to participation and that, on the other hand, this should not be at the exclusion of offline project promotion (e.g., flyers, posters, and events). This is exactly the goal that we are pursuing.

\section{THE STUDY}

The interdisciplinary nature of our work, our interest in social support, which means focusing on connections and relationships among caregivers, and our constructivist perspective, led us to adopt a multi-sited ethnography [44].

Multi-sited ethnographies combine different techniques to define their object of study; among the seven techniques identified in [44], we mobilized two of them: Follow the People (the informal caregivers) and Follow the Metaphor (the social support among informal caregivers). Following the people means being able to follow some informal caregivers who are seeking out or receiving social support from peers in different settings in which they are receiving this support (at home, outdoors, in specific places). Following the metaphor means following the different discourses and registers about social support among informal caregivers that we can encounter in different settings (association, respite care service, at home with informal caregivers, etc.).

Our study is also "multi-sited" because we have recruited participants in two different cities in France, Troyes (NorthEast) and Paris. Our fieldwork has begun in Troyes where the participants are part of a dynamic healthcare network, RéGéMA, which provides them access with several respite and support services (training, support groups, day care services). However, a lot of informal caregivers do not benefit from such local solutions, thus we thought it was important for our research to meet other informal caregivers. We have then extended our data collection to Paris in order to find new participants as detailed in the following section.

\section{Context and Participants ${ }^{1}$}

We obtained access to a group of informal caregivers through a regional healthcare network dedicated to patients suffering from AD, RéGéMA. This organization is coordinated by a psychologist who decided to tackle seriously the burden felt by informal caregivers. She then organized several activities dedicated to providing informal caregivers some support and respite. Thus, in the city of Troyes and through RéGéMA, informal caregivers have access to a portfolio of community care services that gathers several initiatives and activities intended for AD patients and their informal caregivers: support groups, training and respite activities. The healthcare network is not always directly involved; some activities are organized by retirement homes, associations or health and social workers. The network remains, however, a key entry point to pass the information to informal caregivers.

Among the different solutions offered to informal caregivers is L'Embellie, started in June 2013. It is a respite day care service that was initiated at the demand of four "young" AD spousal caregivers (aged 60-65). They met while taking part in the support group meetings organized by RéGéMA. These four "young" spousal caregivers expressed their frustration regarding the available day care services. They thought the options did not fit their situation (even if they managed to use them). They were worried about their spouse being "alone" with older patients (80-90) with more severe conditions. They thought their "young" spouses would have difficulties in developing relationships with the participants and enjoying the very quiet activities organized (e.g., painting, coloring pictures).

This idea of developing a new day care solution dedicated to spousal caregivers aged less than 70 has benefited from the organizational support of the healthcare network. A place in one of the local retirement homes has been found with the help of the network coordinator. The agenda of the solution has been discussed following the idea to provide a

\footnotetext{
1 All the participants names have been changed for anonymity reasons
} 
lunch and respite time with and without the sick relative during the day. Financial resources have also been collected through the RéGéMA funding network (e.g., insurance companies, local foundations, and public subvention). These resources are used for food and drinks, the participation of the retirement home employees, and handwork materials for manual activities during the afternoon sessions. The informal caregivers also pay a fee.

This initiative was an original organization of social support among informal caregivers that seemed to be successful; we then decided to understand their practices, and we met 5 couples and one spousal caregiver who has recently placed her husband in an $\mathrm{AD}$ care unit. All but one of the caregivers were women, aged from 60 to 65 .

After meeting them at one of the sessions of L'Embellie, three participants agreed to welcome us into their homes. These three spousal caregivers are all female (Anna, Helene and Louise), and they take care of their husbands who suffer from AD. These spousal caregivers are aged between 60 and 65 years old, one is suffering from back pain and another has to go to a thermal cure each year to treat breathing difficulties. All are now retired, and the care they are providing to their husbands is at the center of their daily life. Two of them live in the suburbs of Troyes, and the other one lives in a small town, 40 kilometers from Troyes. The three couples are mobile and regularly drive to join the different activities included in the respite services portfolio.

The E-Seniors association based in Paris and dedicated to promoting and providing assistance and teaching ICT to seniors helped us in recruiting other informal caregivers experiencing different situations than the ones in Troyes. The association allowed us to be in touch with some of their members who are assuming the role of informal caregiver and has assisted us in conducting the fieldwork. Our goal of designing an online system dedicated to informal caregivers was presented to prospective participants. Among the interested persons, three women agreed to join the project and to take part in our study: Aline, Bess and Caroline.

The three of them live in Paris, and their ages vary between 69 and 79 years old. The caregiving situations are different compared to the more homogeneous ones we encountered in Troyes. Aline is supporting a woman friend who is nearly 90 and suffers from intense back pain. Bess is caring for her daughter who is affected with schizophrenia. Caroline is taking care of her mother who has had Alzheimer's disease for years and was no longer able to get out of her bed at the time we met. Through their informal caregiver roles, they have contacts with medical and household services, but none of them are benefiting from support and respite services.

None of the participants were using discussion forums or online social support systems to find peers or to get advice on how to perform their role as a caregiver.

\section{Data Collection}

Our data collection is a combination of different techniques in different sites (Table 1). We have joined the sessions organized by L'Embellie two times, one morning and one afternoon, conducting observations of the activities of the participants. We were interested in the activities performed by the informal caregivers and their sick relatives during their stay at the day service. All these observations have been recorded through field notes.

For each of the three couples who welcomed us into their homes, we conducted 3 half-day shadowing sessions. We negotiated with these participants the possibility of balancing our presence between late mornings and afternoons. Through this strategy, we had the opportunity to attend one of the yoga courses organized in the framework of the respite services for family caregivers. During the course, their sick relatives were at the day care service provided by the retirement home. We also observed one inhome respite session. All these observations have been recorded through field notes. To supplement our understanding of this respite care solution led by the informal caregivers themselves, we conducted three individual semi-structured interviews with the spousal caregivers we followed during the shadowing sessions. In these interviews, we focused on the current support these caregivers benefit from, especially by taking part in L'Embellie. We also discussed their use of ICT. These three interviews were recorded and transcribed.

Following the same approach as in Troyes, the participants from Paris were asked to agree to be shadowed for 3 halfdays and be interviewed after the shadowing period. A focus group has also been organized to benefit from the participants' feedback on the preliminary results of our analysis. We focused especially on the form of support the participants find in their daily life and their current use of ICTs. As the participants in Paris never met before our study, the focus group was an opportunity to meet each other and discuss their different situations. Shadowing sessions were not performed at home for Bess due to the paranoid disorder of her daughter. The observations were nevertheless consistent with Bess's habits as she is used to going out a lot (she was followed when she went out for shopping or to the café) to preserve her daughter's preference for loneliness and to cope with her troubles. Caroline ended up not being able to have someone shadow her at home, but she managed to take part in the focus group.

The observations have been recorded through field notes. Semi-structured interviews performed individually with the three of them have been conducted following the same grid used in Troyes and with the aim of supplementing our understanding of the shadowing sessions (when they took place). We also discussed their current use of ICT. The interviews and the focus group session have been recorded and transcribed. 


\begin{tabular}{|c|c|c|}
\hline Sites & $\begin{array}{c}\text { Informal } \\
\text { caregivers }\end{array}$ & Techniques \\
\hline \multicolumn{3}{|l|}{ Troyes } \\
\hline L'Embellie & $\mathrm{N}=6$ & $\begin{array}{c}\text { Observation } \\
\text { ( } 2 \text { half-days }-8 \text { hours) }\end{array}$ \\
\hline $\begin{array}{l}\text { Respite services } \\
\text { (yoga) }\end{array}$ & $\mathrm{N}=4$ & $\begin{array}{c}\text { Observation } \\
\text { (1 session }-3 \text { hours })\end{array}$ \\
\hline $\begin{array}{c}\text { Informal caregivers' } \\
\text { homes }\end{array}$ & $\mathrm{N}=3$ & $\begin{array}{l}\text { Shadowing }(9 \text { half- } \\
\text { days }=27 \text { hours }) \text {, semi- } \\
\text { structured interview }(3 \\
* 2 \text { hours })\end{array}$ \\
\hline \multicolumn{3}{|l|}{ Paris } \\
\hline $\begin{array}{c}\text { Informal caregivers } \\
\text { home }\end{array}$ & $\mathrm{N}=2$ & $\begin{array}{l}\text { Shadowing }(6 \text { half- } \\
\text { days }=18 \text { hours }) \text {, semi- } \\
\text { structured interview }(2 \\
* 2 \text { hours })\end{array}$ \\
\hline E-Seniors office & $\mathrm{N}=4$ & Focus group (4 hours) \\
\hline
\end{tabular}

Table 1. Data collection synthesis

\section{Data Analysis Approach}

Our analysis is guided by the grounded theory approach to qualitative data analysis [63]. From the beginning of the study, field notes have been used as material for open coding. The recurrent themes have been identified and attached to analysis codes, and were refined after several iterations. We focused especially on the forms of support the informal caregivers' value, and the practical opportunities for receiving social support they experience in their daily life.

The coded data has been discussed among all the researchers involved in this project (from three different European countries) in order to create the interview guide. The transcripts of the interviews have been coded on the basis of the previous step and extended to new issues. It led us to identify four themes related to the forms of support the informal caregivers value and find in their daily life: feeling that you are not alone, continuing leisure activities, learning from others and sustaining participation.

In line with the theoretical sampling approach to fieldwork, these themes have been prompted and checked for relevance during the following meetings with the participants, especially during the focus group. Without pretending to achieve saturation of our data analysis, the highlighted themes helped us to elaborate the four design opportunities we discuss later in the paper.

\section{FINDINGS}

The problems and solutions experienced by informal caregivers, the activities they perform or are willing to do, and their relationships with other informal caregivers and people in their environment can be categorized under four themes: feeling that you are not alone, continuing leisure activities, learning from others, and sustaining participation. After having presented how the participants currently make use of ICT, we illustrate the four themes we have identified with quotations from our participants that have been translated from French.

\section{Feeling that you are not alone}

The informal caregivers we met stressed the importance of being able to talk about their care situation and the problems they encounter. As one of the participants expressed, the loneliness is sometimes high.

(Caroline, 196 - Focus group): "Especially with my mother, you have the impression of talking to the ceiling..."

When a crisis occurs, friends or relatives can provide a listening ear.

(Bess, 111 - Interview) "Well, it is always good to know that you are not the only one who has problems. And I have several friends who have elderly mothers, or a friend whose son had a stroke when he was 40, so you see. It makes you feel, this is not a very nice thing to say, but it makes you feel that their problems are worse. (Laughing)"

However, getting help from friends or family is not guaranteed. In fact, most of the informal caregivers are lonely either because their family lives far away from them or because no one they know is available.

(Louise, 81 - Interview): "Because often, as it is the case for us, all the members of the family are working. I still have my parents-in-law, but they are old; my father-in-law cannot drive anymore. On the other side, my mother is old too, around 87-88. Then, you cannot really count on the family. Then, you cannot stop that."

Another problem is related to the feeling of not being understood by relatives who do not realize the magnitude of the situation. Louise complains about her mother-in-law, who is always comparing the situation Louise is living with to caring for a very old person, who could be demented too, but calm, without major behavioral disorders.

(Louise, 93 - Interview) "I try to make her understand... to bring the problem up again. But she is always coming back to the others who are 87 years old and I tell her: 'so, there is one person who is younger just there!' "

Institutions and associations can also offer support, especially in meeting people experiencing similar situations. Support groups and other occasions for meeting peers are therefore evoked as an important source of help.

(Helene, 212 - Interview) "When we are in the group, indeed, it's not always easy to talk. But on the other hand, this is of great help because you can get it off your chest."

Moreover, the fact that those in the immediate environment are aware of the difficult situation they face is presented as a way to protect the informal caregivers in case of problems. 
(Bess, 172 - Interview): "when she was really sick and even aggressive with me, I decided to tell about our situation to other people, so I told the hotel manager across the street about it, the pharmacist, the general practitioner. Because I was feeling that if she became really aggressive one night, I could run to somebody. So now, at least they know my story."

Isolation also raises issues for informal caregivers who have not chosen and have not been trained for this role, whether they act in the right way when they take care of their relative. To talk with others regarding the situation appears to be not only a way to relieve stress but also a way to receive essential feedback to know if their situation would be perceived as "normal," given the pathology.

\section{Continuing Leisure Activities}

All the caregivers we met are retired and envisioned their retirement as a time to enjoy life and participate in many leisure activities. However, the disease of their beloved one or close relative and the fact that they had to take on this new role as caregiver changed their plan. Travelling, going outside for a walk or simply going to a restaurant or movie theater became complex due to the condition of the care receiver.

Two spousal caregivers of AD patients have told us of the bad experience they had when they participated in a tour package to the city of Lourdes (France). The travel was organized by a local association and was not dedicated to informal caregivers of $\mathrm{AD}$ patients. The journey was so stressful for their sick husbands that at some point they did not want to get off the bus. The spousal caregivers had to ask a doctor to prescribe tranquilizers to their husbands so they could sleep at night.

Another spousal caregiver told us that the last three years they have been going to a thermal cure that is seven driving hours away. They have to manage the journey in two days to take time and never be in a hurry. The main problem for her husband is changing his living place and then his habits. It takes him several days to get used to a new place. She told us that she cannot imagine being able to travel to foreign countries anymore, as they used to do.

Except travel, leaving the house and enjoying outdoor activities are cited as important needs.

(Aline, 113 - Interview): "Meeting people of my age and going outside, because sometimes the situation is a bit oppressive. I like to go outside and have a drink. It is a bit like when children are allowed to leave the class for playtime."

(Bess, 119 - Interview) "[I need to do] something totally different [from caregiving], like to go watch movies or outdoor dancing. Totally different I mean."

The experience of the spousal caregivers in Troyes also highlights three types of obstacles to enjoying leisure: (1) being accepted and participating like everyone else, (2) planning the event and finding a solution for monitoring their ill relative, and (3) finding the motivation to participate in activities.

One spousal caregiver told us their experience upon arrival to the local astronomy club, after her husband suffering from AD wished to participate (Helene, 26, Shadowing field notes). Although she explained the situation to the manager of the club in advance, the hosts were not patient at all and expressed their annoyance with sometimes strange but enthusiastic questions asked by her husband. After a few sessions, his wife decided to stop their participation and resell the expensive telescope that she had bought her husband.

Another couple reported the same type of difficulties; they had to stop participating in a trekking club because participants were not willing to wait for them when the evolution of the husband's disease forced him to walk more slowly (Anna, 19, Shadowing field notes).

When the care receiver is still able to participate in leisure activities, organizing requires effort because it means planning the participation of the sick relative and then dealing with potential problems, which may discourage the informal caregiver. However, the situation is not easy even when the care receiver is no longer able to participate. In this case, the caregiver must find and arrange supervision solutions for her/his relative (for instance, through a day care service) to enjoy some respite. For this purpose (as we have observed in Troyes), community care services offer a solution for the participation of the sick relatives or their supervision when they provide activities specifically designed for informal caregivers (such as yoga, dance or informatics courses, and even group trips). For example, during our shadowing sessions, two of the participants in our study attended a yoga session in a retirement home while their sick relatives were cared for by an employee of the retirement home.

The dedicated activities offered by community care services are relevant because they allow for overcoming the top two barriers to participation (being accepted and finding a solution for the sick relative during this time). However, another obstacle to leisure is a lack of motivation. In this case, being part of a group that meets regularly seems to be the key to staying motivated.

(Louise, 81 - Interview) "This encourages us. And at least, this makes us leave the home. Because sometimes, going out only us two, that's not... Especially when he is not feeling well."

What seems important is not the type of activities offered but rather that participating permits meeting other people living in the same situation, as indicated by a participant regarding the informatics course: 
(Helene, 697 - Interview): "Even if it doesn't bring me much, that's a respite time. Because we exchange, we will talk about something else. During this time, they [the care receiver] are watched over by Monica or one of the [retirement home employees], they are kept busy, they are doing things too."

The latter quote also highlights the importance, especially for spousal caregivers, of including their sick spouse in their leisure activities. When the participation of all is possible, as at L'Embellie or during dancing classes, the group provides a convenient way to monitor and deal with the sick relatives. For instance caregivers who participate in L'Embellie can count on the group to help them handle the situation if their sick relative tries to go outside or appears to be in trouble. During one of our visits, a spousal caregiver even took a nap while the other participants were doing craftwork. She felt confident enough to trust her husband to the care of the other group members.

\section{Learning from Others}

The need of a person who is just beginning to be an informal caregiver to access information and knowledge has been described [8] and is of course a reality for our participants. The question of how to provide "good" care to their ill relative and how to react in the right way has been discussed several times in our study, such that a participant speaking of the difficulty of handling a discussion about death said that:

(Aline, 49 - Interview) "We are somewhat helpless to respond to such conversations. And for the person [care receiver] in front of you, that's something real, and if this person wants to talk about it, you should not always say 'I don't want to talk about it.' So having support group to talk about a specific topic like that would be of interest."

Among our participants, those who do not take part in a community care service have expressed their expectations for answers and advice from health professionals.

(Bess, 290 - Focus group) "We need a kind of SOS line... this is hard to start, but if you find a system to share emergencies... because that's so important."

Being part of community care services such as L'Embellie and support groups is indicated as a great source of advice.

(Louise, 13 - Interview) "That's a way to gather us in order to teach each other how to handle paperwork, with all these small things we can forget, the notary for instance, things like that. We give each other ideas."

Louise also emphasized the importance of exchanging knowledge and good practices among family caregivers.

"There are persons who are at later stages [of the disease] than us, thus they can provide advice to those who are at an earlier stage..."

The group that formed around the community care services in Troyes is also a way to learn what the possible aids are and how to benefit from them. Indeed, receiving financial assistance or benefit from a home-help or in-home respite hours demands substantial work of family caregivers because they have to fill out paperwork and plan. For example, in France, people with loss of autonomy can receive financial aid from the local government related to their level of autonomy. Obviously, most of the sick, especially those suffering from $\mathrm{AD}$, cannot fill out the required forms and procedures. To get this help, their informal caregiver must obtain a certificate from their general practitioner and arrange a visit with a social worker to evaluate the degree of autonomy of their relative. During support groups and respite services, informal caregivers have become used to sharing experiences on how to access these various aids and services.

Discussing and learning from the experience of others is also a way to find motivation in the implementation of aid and respite solutions. Louise's case illustrates the way most users utilize respite care services; and she did not feel comfortable with the idea of leaving her husband for an entire day; she worried that he would miss her and that he would not be interested in the activities offered by the respite service. When we met her for an interview four months after our first visit, she told us that the experience of a day care service reported by a participant of L'Embellie finally helped her make the decision to send her husband to the same day care service. This allowed her to participate in some activities on the side during this time.

\section{Sustaining Participation}

In Troyes, the people we met were all taking part in a community care service that provides them support and respite through the organization of different activities dedicated to informal caregivers (support groups, day care services, training and relaxing activities). However, as Helene explained, not all informal caregivers wish to participate in these activities.

(Helene, 200 - Interview): "There are François, Louise, etc. But there are always the same ones. We never see all the persons who are followed by RéGéMA [the healthcare network]. They are not participating. Even when they are mobile; but, they do not want to anyway."

As we already mentioned, informal caregivers encounter several constraints that prevent them from joining the support and respite activities that are offered. Moreover, not every caregiver is interested in the proposed activities, sometimes because their sick relative disagrees with participating.

(Helene, 204 - Interview): "For example, Paul YYY, at some point he was coming with his wife Marine. Marine, she is no more willing to come; she has the disease, who knows why..."

Although the participation of the six hundred people followed by RéGéMA in all activities is not feasible, developing and sustaining the informal caregivers' interest 
is necessary to ensure the existence and funding of respite and support services.

Some activities appear more appealing than others, as explained by Helene.

(Helene, 526 - Interview): "Then you go to the support group, Anna, Louise, sometimes François and so 4 people for sure. You launch an invitation for a trip and you got 35 persons! You see, support groups and training, not a lot of people are interested in. But as soon as you say 'We will eat out', then they are all there."

Informal caregivers are also concerned about no longer being considered caregivers by the administration in the future, when their sick relatives pass away or are placed in nursing homes. Louise explained the case of a participant of L'Embellie who had to place her husband in an AD unit. Her participation in the community care service activities has become much more complicated. One of the reasons why she cannot participate anymore is related to the insurance that covers the associations or organizations that establish the activities. In fact, the insurance policy would not cover her presence as she is not an informal caregiver anymore from an administrative point of view.

(Louise, 109 - Interview): "And I say that's sad, because sometimes, you need it after all that. Yes, to continue. At L'Embellie, me, I have always seen her. That's sad because there is this cut as soon as our husband is placed or whatever."

In fact, the community care services remain available until the end of the year when the care receiver has left home; nevertheless, the perspective of being deprived of support and respite services adds to the distress or guilt felt when leaving the sick relative in a care institution.

\section{DISCUSSION ON HOW TO EXTEND OFFLINE RESPITE AND SUPPORT}

The informal caregivers we met and the analysis of the different sources of respite and support they find in their daily life emphasize the fact that they are looking for solutions to fight the loneliness and isolation they are feeling, mainly caused by the burden of being a caregiver. The experiences they shared with us highlighted the benefit they get from social interactions. Family and friends appear as a source of support; however, their availability and ability to understand may be missing. Thus, our analysis showed the benefits of taking part in a group of peers (other informal caregivers).

In addition to the fight against social isolation, sharing experiences with people in the same situation is also a way of being reassured about the "normality" of the problem they face, particularly regarding the highly emotional and daily troubles that are caused by a person with cognitive disorders. Sharing how they manage these everyday problems is also a way to be reassured regarding the decisions and choices they make when they take care of their sick relative. Sharing experiences with peers is also a way to address the gap between the medical discourse on the "proper" way to care for a person with a loss of autonomy and practical problems that caregivers encounter daily, as highlighted by Brereton and Nolan [8]. Adapting and performing care at home causes many worries for untrained informal caregivers who try to do their best. Thus, the experience of former or more experienced informal caregivers is important and highly valued.

We have also found, well-illustrated by the case of Louise, that a group of peers is a way to be encouraged and to learn how to implement the different existing respite and support services that are offered. Getting feedback on the benefits that other informal caregivers using these services receive is a key motivation to complete the necessary extra work (paperwork and planning) that is associated with the implementation of these solutions (i.e., day care services, in-home respite visits).

Gathering a group as small as two couples or larger also acts as a facilitator for enjoying leisure activities. The gym, dance or informatics courses offered by the community care services are well-appreciated because these activities take into account the care receiver. The relationships that are developed in this framework provide a good basis for organizing other activities and trips, such as going bowling or attending a concert. The group helps in finding motivation to go out of the home and to feel stronger when people "from outside" seem exclusionary.

Most of our findings highlight different forms of support related to the development of social relationships and activities that take place in the "offline world". The themes we have identified through our analysis of the discourses and registers of respite and social support for informal caregivers are valuable and are helping to give us a basis to discuss the beneficial role that ICT can play in such a context. In what follows, we propose four design opportunities that illustrate how ICT could be integrated in the respite and support solutions we have observed and studied. These design perspectives are not breakthrough innovations, we can find some of the features in existing online solutions, but for elderly informal caregivers it is difficult to be aware of all these existing solutions, or even to manage to combine them. We are then interested in: (1) integrating these features in a unique online platform that would cover the different dimensions of social support [64], and (2) in exploring how these online activities could complement offline ones..

\section{Finding peers}

Being aware that other people are facing the same situation and being aware of how they manage it appears to be an important form of support to fight against loneliness and also to see the situation as "normal." What we want to emphasize here is that the idea of knowing that another person is in the same situation, even if it is only by looking 
at a webpage, is a form of support. Thus, browsing and lurking on profiles and conversations is also a way of receiving social support [24].

One implication for the design of an online social support system dedicated to informal caregivers would be to then emphasize the presence of the people who share a similar caregiving situation (peers). This presence of peers could be visible on the home page and through interface components. For instance, a global interactive chart with the profile pictures of the members on the home page is an interesting option. A dedicated search engine for members' profiles is also essential to favor peer finding.

Moreover, what makes a situation similar from one informal caregiver to another is not only the disease of their relative but also the relationship with the sick person (being a spouse, a child, a parent or a friend), the stage of the disease, the age (of the caregiver and the care receiver), and their location. The fieldwork we have conducted is an important resource for defining these elements to design an appropriate and useful profile page that will encourage finding and interacting with peers.

As mentioned earlier, several studies [2,40,49,66,71,72] have already offered various solutions, emphasizing more or less the problem of engaging participation. In our study, several participants mentioned that, unfortunately, not all the informal caregivers from RéGéMA are taking part in the respite and support services linked to RéGéMA, whereas they could benefit from them. Our study of l'Embellie highlights the key role of the coordinator of RéGéMA in motivating several informal caregivers from Troyes to meet and to develop the innovative respite solution (l'Embellie). She is, in particular, playing an important role by introducing informal caregivers to each other and encouraging them to exchange contact details and continue discussing.

This mediation from a professional could be integrated into our approach when deploying the online social support application to encourage the informal caregivers who are only lurkers to start participating in social activities (online and offline).

\section{Being Aware of Leisure Activities}

The data that we have collected made clear that informal caregivers are definitively interested in continuing leisure activities outside of their home. An online application could ease coordination and extend the participation of informal caregivers in activities in their local environment.

Indeed, if ICT can hardly address the three identified barriers to participation - being accepted by others, managing the care receiver participation, and being motivated - being aware of an event that one is taking place could at least multiply the opportunities to go out of the home and to meet other people who understand the particular situation of being an informal caregiver. It could also extend serendipitous participation in initiatives to more members, as in the following reported by Helene:

(Helene, 539 - Interview): "[Interviewer: Internet could be a tool to propose events, like: we have seen there is an exhibition organized there. We plan to go, feel free to join]. Yes. That's the way we found ourselves last Sunday at Aix [the city of Aix-en-Othe] for the New Year concert of l'Harmonie des Chemins de fer de Romilly-sur-Seine. Free event. Then, as Anna always had to move in the afternoon because of Marcus, he needs to move. I told her, if you want, come with us to Aix, there is a concert."

An important feature could also be to provide a space to share recommendations about local associations or clubs where the participation of informal caregivers with their sick relatives is welcomed. Enabling the sharing of photos and messages related to events and organized activities would also be an important feature to encourage participation of informal caregivers with their sick relative.

However, regarding their overwhelmed daily life, asking informal caregivers to publish information about associations or local events appears difficult. Following the work done by researchers involved in Living Lab approaches for designing ICT in sensitive settings $[45,48]$, we believe that a key factor for the implementation and sustainability of such an online system is to engage and provide space to local associations and respite services to make visible the activities they are offering.

\section{Building a Common Knowledge Base}

An online social support system is an opportunity to build a common knowledge base for the informal caregivers to share their experience. In fact, we observe that, when an informal caregiver sees the disease of her or his relative evolving, or when newcomers arrive in the support group, nearly the same discussions and advice pop up. A feature for an online social support system could be to provide access to a common knowledge base but also to support discussion and knowledge transmission between peers.

We propose to use folksonomies [75] to ease informal caregivers' searches in such a knowledge base. We suggest scaffolding tips and advice mentioned during online discussions taking place on the system with tags. The informal caregivers will then be able to tag a message in which she/he identifies an interesting piece of advice. The wording of the tag can be chosen by the informal caregiver or selected from lists of health issues (i.e., Alzheimer's disease, Parkinson's disease, Sleep apnea, Back pain), daily situations (i.e., sleeping, bathing, going outdoor, taking medicines, paperwork) or places (i.e., bedroom, bathroom, corridors, stairs, kitchen). For bootstrapping these lists of tag values, it is essential to combine the material collected from fieldwork with new tags that will be created by the informal caregivers using the online system. An important and interesting aspect of this tagging solution for building a 
knowledge base is that it preserves the conversational context in which the knowledge was expressed.

Experienced informal caregivers are thus an important source of knowledge for informal caregivers who are beginners or less experienced. Our online application could be a place where former caregivers (whose relative passes away) can continue making sense of their experience and help in passing knowledge and support to newcomers. In the framework of local support and respite services, a type of mentoring program associated with our online application would be an interesting solution to explore.

\section{Participating Online to Extend Face-to-Face Discussions}

Taking care of the care receiver, having to drive, or time constraints are identified as barriers to join activities with other informal caregivers. These constraints hamper the possibility of developing supportive relationships, such as the ones created by the participants in Troyes. Even if faceto-face relationships appear the most valued by all our participants, the Internet has great potential because it relaxes time and geographical constraints.

Thus, an online social support system could enable groups of informal caregivers like the one we met in Troyes, as well as local respite and support services, to reach and connect other informal caregivers who are not participating in the existing offline services. A promising way to do that could be to provide online channels to continue the discussions that take place during support groups or during the activities organized by the community care services. We can also imagine discussing the topics raised in online conversations during face to face support group meetings, for instance. Here, the technological needs and means are not new (chat and forum features), but the fine tuning of these features for the coordinator of a support group and its members, as well as the way to introduce the feature and to foster participation, involves important mediation work.

As we have seen in our results, another aspect reported by our participants lies in the risk of being excluded from support and respite services as soon as the care receiver leaves the home, for instance, to go to a nursing home. In fact, in France, most of the help is related to the situation of the sick person. This means that, if the sick relative is placed in a nursing home or dies, the informal caregiver formally loses her/his caregiving role and all the related offered meetings and activities. Knowing that institutionalization or death are stressing events that make critical the access to supportive relationships, an online support system could offer a place for "former" informal caregivers to maintain the relationships they built with the persons they met through the community care services.

\section{CONCLUSION}

While a number of research studies have focused on isolated informal caregivers coordinating with professionals in caring for a sick relative at home or on the personal experience of informal caregivers, we instead aimed to understand the practical conditions of effective social support practices of older informal caregivers.

Our contributions can be summarized as follows. First, we offer this fine-grained description of the social support older informal caregivers receive and value. Our analysis emphasizes that being aware of other persons going through a similar situation and of the way they are dealing with it is already a form of social support. We have also highlighted that being part of a group appears to be an important means for informal caregivers to fight isolation, learn and be reassured in assuming their caregiver role and to encourage the adoption of available help. This confirms and extends existing nursing studies $[8,38]$, and complements studies of social support taking place online $[4,29,34,36,43,50$, $60,67,69]$, that mainly concern patients or younger caregivers. We also provide design perspectives, that contrary to existing work on the design of online systems to foster social interactions among elderly people or informal caregivers $[2,40,49]$, do not exclude online and offline activities but rather try to bridge them. With these design perspectives, we offer potential practical solutions to open issues existing in work claiming that encouraging online participation should not be done at the exclusion of offline services promotion [62,21]. Maintaining and sustaining group relationships through ICT appears to be a promising way to provide access to effective social support to a great number of older informal caregivers, and to contribute to diminish the barriers for older adults to participate in online communication and therefore online support [19].

Whether and how ICT can help in building groups remains a complex research question. The solutions we propose follow a socio-technical approach [1] and involve much work to define the intervention to accompany the deployment and use of online features aimed at easing participation in both offline and online group activities. We also suggest that technological support could be promising for sustaining participation or staying in touch with others even when an informal caregiver is no longer "recognized" as such by the institution. Further work is still needed to design and implement meaningful and relevant tools that will be based on the current social support practices and that will have their potential fully developed with local actors. We are currently organizing workshops with the participating informal caregivers to refine the design options we have presented, and we will involve these participants in a longitudinal field evaluation as soon as these design options are implemented and tested.

\section{ACKNOWLEDGMENTS}

We thank all the participants of L'Embellie, RéGéMA and E-Seniors.

This work has been supported by European Union, ANR and national solidarity fund for autonomy through AAL program (project AALI 2012-TOPIC). 


\section{REFERENCES}

1. Mark S. Ackerman. 2000. The Intellectual Challenge of CSCW: The Gap Between Social Requirements and Technical Feasibility. Human-Computer Interaction 15, 2-3: 179-203.

2. Malek Alaoui and Myriam Lewkowicz. 2012. Struggling against Social Isolation of the Elderly - The Design of SmartTV Applications. In From Research to Practice in the Design of Cooperative Systems: results and Open Challenges, Proceedings of the 10th International Conference on the Design of Cooperative systems, Julie Dugdale, Cédric Masclet, Maria A. Grasso, Jean-François Boujut and Parina Hassanaly (eds.). Springer, London, UK, 261-276. http://dx.doi.org/10.1007/978-1-4471-4093-1_18

3. Melanie K. Barnes and Steve Duck. 1994. Everyday communicative contexts for social support. In Communication of social support: Messages, interactions, relationships and community, Brant R. Burleson, Terrance L. Albrecht and Irwin G. Sarason (eds.). Sage, Thousand Oaks, USA, CA, 175-194.

4. Edwin Blake. 2007. Information and social support for semi-literate people living with HIV. Interactions 14 , 5: 29-32. http://dx.doi.org/10.1145/1288515.1288535

5. Susanne Bødker and Erik Grönvall. 2013. Calendars: Time coordination and overview in families and beyond. In Proceedings of the 13th European Conference on Computer Supported Cooperative Work (ECSCW 2013). Springer, London, 63-81. http://dx.doi.org/10.1007/978-1-4471-5346-7_4

6. Claus Bossen, Lars Rune Christensen, Erik Grönvall, and Lasse Steenbock Vestergaard. 2013. CareCoor: Augmenting the coordination of cooperative home care work. International journal of medical informatics 82, 5: e189-e199.

7. Tone Bratteteig and Ina Wagner. 2013. Moving healthcare to the home: The work to make homecare work. In Proceedings of the 13th European Conference on Computer Supported Cooperative Work (ECSCW 2013). Springer, London, 143-162. http://dx.doi.org/10.1007/978-1-4471-5346-7_8

8. Louise Brereton and Mike Nolan. 2000. "You do know he's had a stroke, don't you?" Preparation for family care-giving-the neglected dimension. Journal of clinical nursing 9, 4: 498-506.

9. Robert J. Buchanan, Chunfeng Huang and Adele Crudden. 2012. Use of the Internet by informal caregivers assisting people with multiple sclerosis. Journal of Technology in Human Services. 30, 2: 7293. http://dx.doi.org/10.1080/15228835.2012.700558

10. Yunan Chen, Victor Ngo, and Sun Young Park. 2013. Caring for Caregivers: Designing for Integrality. In Proceedings of the 2013 Conference on Computer
Supported Cooperative Work (CSCW '13). ACM, New York, 91-102. http://doi.org/10.1145/2441776.2441789

11. Lars Rune Christensen and Erik Grönvall. 2011. Challenges and opportunities for collaborative technologies for home care work. In Proceedings of the 12th European Conference on Computer Supported Cooperative Work (ECSCW 2011). Springer, London, 61-80. http://dx.doi.org/10.1007/978-0-85729-913-0_4

12. Teresa Chiu, Elsa Marziali, Angela Colantonio, Anne Carswell, Marilyn Gruneir, Mary Tanga and Gunther Eysenbach .2009. Internet-based caregiver support for Chinese Canadians taking care of a family member with Alzheimer disease and related dementia. Canadian Journal on Aging, 28, 4: 323-336. http://dx.doi.org/10.1017/S0714980809990158

13. David Constant, Lee Sproull and Sara Kiesler 1996. The kindness of strangers: The usefulness of electronic weak ties for technical advice. Organization Science 7, 2: 119-135. http://dx.doi.org/10.1287/orsc.7.2.119

14. Neil S. Coulson. 2005. Receiving social support online: an analysis of a computer-mediated support group for individuals living with irritable bowel syndrome. CyberPsychology \& Behavior 8, 6: 580-584.

15. Matty Cruijsberg, Martijn H. Vastenburg, and Pieter Jan Stappers. 2012. Family Carebook: A Case Study on Designing Peace of Mind for Family Caregivers. In Ambient Intelligence-Software and Applications, Paulo Novais, Kasper Hallenborg, Dante I. Tapia et al. (eds.). Springer, Berlin, 129-136. http://dx.doi.org/10.1007/978-3-642-28783-1_16

16. Pavan Dadlani, Alexander Sinitsyn, Willem Fontijn, and Panos Markopoulos. 2010. Aurama: caregiver awareness for living independently with an augmented picture frame display. Ai \& Society 25, 2: 233-245.

17. Karen Donelan, Craig A. Hill, Catherine Hoffman, Kimberly Scoles, Penny Hollander Feldman, Carol Levine and David Gould. 2002. Challenger to care: Informal caregivers in a changing health system. Health Affairs 21, 4: 222-231. http://dx.doi.org/10.1377/hlthaff.21.4.222

18. Elizabeth H. Ehleringer and Si Jung Kim. 2013. The Wearable Lullaby: Improving Sleep Quality of Caregivers of Dementia Patients. In CHI '13 Extended Abstracts on Human Factors in Computing Systems (CHI EA '13). ACM, New York, 409-414. http://doi.org/10.1145/2468356.2468429

19. Michailidou Eleni, Antigoni Parmaxi and Panayiotis Zaphiris. Culture effects in online social support for older people: perceptions and experience. Universal Access in the Information Society 14, 2: 281-293. http://dx.doi.org/10.1007/s10209-014-0346-3

20. Nicole B. Ellison, Charles Steinfield, and Cliff Lampe. 2007. The benefits of Facebook "friends:" Social 
capital and college students' use of online social network sites. Journal of Computer Mediated Communication 12, 4: 1143-1168.

21. Sheena L. Erete. 2015. Engaging Around Neighborhood Issues: How Online Communication Affects Offline Behavior. In Proceedings of the 18th ACM Conference on Computer Supported Cooperative Work \& Social Computing (CSCW '15). ACM, New York, 1590-1601. http://dx.doi.org/10.1145/2675133.2675182

22. Susannah Fox and Joanna Brenner. 2012. Family Caregivers Online. Washington, DC: Pew Research Center. Retrieved January 5, 2016 from http://pewinternet.org/Reports/2012/Caregiversonline.aspx

23. Carolina Fuentes, Valeria Herskovic, Jurgen Heysen, and Monica Tentori. 2013. Towards a technology for caregivers' emotional expression and self-reflection. In Ubiquitous Computing and Ambient Intelligence. Context-Awareness and Context-Driven Interaction, Gabriel Urzaiz, Sergio Ochoa, José Bravo et al.(eds.). Springer International Publishing, 143-150. http://dx.doi.org/10.1007/978-3-319-03176-7_19

24. Gérald Gaglio. 2010. Consommation d'informations sur Internet et modulation de la relation aux médecins. Le cas d'aidantes de malades atteints d'une pathologie lourde. Sociologies pratiques 20, 1: 63-74.

25. Eva Ganglbauer, Geraldine Fitzpatrick, Özge Subasi, and Florian Güldenpfennig. 2014. Think globally, act locally: a case study of a free food sharing community and social networking. In Proceedings of the 17th ACM conference on Computer supported cooperative work \& social computing (CSCW '14). ACM, New York, 911-921. http://doi.org/10.1145/2531602.2531664

26. Kathrin M. Gerling, Matthew Miller, Regan L. Mandryk, Max V. Birk, and Jan D. Smeddinck. 2014. Effects of Balancing for Physical Abilities on Player Performance, Experience and Self-esteem in Exergames. In Proceedings of the 32nd Annual ACM Conference on Human Factors in Computing Systems (CHI '14), ACM, New York, 2201-2210. http://dx.doi.org/10.1145/2556288.2556963

27. Nancy L. Green, Curry Guinn, and Ronnie W. Smith. 2012. Assisting social conversation between persons with Alzheimer's disease and their conversational partners. In Proceedings of the Third Workshop on Speech and Language Processing for Assistive Technologies (SLPAT '12). Association for Computational Linguistics, Stroudsburg, USA, 37-46.

28. Andrea Grimes, Brian M. Landry, and Rebecca E. Grinter. 2010. Characteristics of shared health reflections in a local community. In Proceedings of the 2010 ACM conference on Computer supported cooperative work (CSCW '10). ACM, New York, NY,
USA, 435-444.

http://dx.doi.org/10.1145/1718918.1718992

29. David H. Gustafson, Robert P. Hawkins, Eric W. Boberg, Fiona McTavish, Betta Owens, Meg Wise, Haile Berhe and Suzanne Pingree. 2002. CHESS: 10 years of research and development in consumer health informatics for broad populations, including the underserved. International Journal of Medical Informatics 65, 3: 169-177. http://dx.doi.org/10.1016/S1386-5056(02)00048-5

30. Dave Harley and Geraldine Fitzpatrick. 2009. YouTube and intergenerational communication: the case of Geriatric1927. Universal access in the information society 8, 1: 5-20. http://dx.doi.org/10.1007/s10209-008-0127-y

31. Susan C. Herring. 2002. Computer-mediated communication on the Internet. Annual Review of Information Science and Technology 36, 1: 109-168. http://dx.doi.org/10.1002/aris.1440360104

32. Michael Hirst. 2005. Carer distress: A prospective, population-based study. Social Science \& Medicine. 61, 3: 697-708. http://dx.doi.org/10.1016/j.socscimed.2005.01.001

33. Ai-Ju Huang, Hao-Chuan Wang, and Chien Wen Yuan. 2014. De-virtualizing social events: understanding the gap between online and offline participation for event invitations. In Proceedings of the 17th ACM conference on Computer supported cooperative work \& social computing (CSCW '14). ACM, New York, NY, USA, 436-448. http://dx.doi.org/10.1145/2531602.2531606

34. Jina Huh and Mark S. Ackerman. 2012. Collaborative help in chronic disease management: supporting individualized problems. In Proceedings of the ACM 2012 conference on Computer Supported Cooperative Work (CSCW '12). ACM, New York, NY, USA, 853862.http://dx.doi.org/10.1145/2145204.2145331

35. Jane Jenson and Stéphane Jacobzone. 2000. Care allowances for the frail elderly and their impact on women care-givers, OECD Labour Marker and Social Policy Occasional Paper, 41 (July 2000). http://dx.doi.org/10.1787/414673405257

36. Ulrika Josefsson. 2003. Patients' Online Communities Experiences of emergent Swedish self-help on the Internet. In Proceedings of the First International Conference on Communities and Technologies (C\&T 2003), 369-389. http://dx.doi.org/10.1007/978-94-0170115-0_19

37. Andrea Kavanaugh, Carroll, John, Mary-Beth Rosson, Than Than Zin, and Debbie Denise Reese. Community networks: Where offline communities meet online. Journal of Computer-Mediated Communication 10, 4 (2005). Blackwell Publishing Ltd, pp. 1083-6101 http://dx.doi.org/10.1111/j.1083-6101.2005.tb00266.x 
38. Haejung S. Lee, Patricia F. Brennan and Barbara J. Daly. 2001. Relationship of empathy to appraisal, depression, life satisfaction and physical health in informal caregivers of older adults. Research in Nursing \& Health 24, 1: 44-56. http://dx.doi.org/10.1002/1098240X(200102)24:1<44::AID-NUR1006>3.0.CO;2-S

39. Hong Li. 2015. Informal Caregivers' Use of the Internet for Caregiving Information. Social work in health care 54, 6: 532-546. http://dx.doi.org/10.1080/00981389.2015.1045577

40. Leslie S. Liu, Sen H. Hirano, Monica Tentori, et al. 2011. Improving communication and social support for caregivers of high-risk infants through mobile technologies. In Proceedings of the ACM 2011 conference on Computer supported cooperative work (CSCW '11). ACM, New York, 475-484. http://dx.doi.org/10.1145/1958824.1958897

41. Leslie S. Liu, Jina Huh, Tina Neogi, Kori Inkpen, and Wanda Pratt. 2013. Health vlogger-viewer interaction in chronic illness management. In Proceedings of the SIGCHI Conference on Human Factors in Computing Systems (CHI '13). ACM, New York, NY, USA, 4958.http://dx.doi.org/10.1145/2470654.2470663

42. Xingjie Liu, Qi He, Yuanyuan Tian, Wang-Chien Lee, John McPherson, and Jiawei Han. 2012. Event-based social networks: linking the online and offline social worlds. In Proceedings of the 18th ACM SIGKDD international conference on Knowledge discovery and data mining (KDD '12). ACM, New York, NY, USA, 1032-1040. http://doi.org/10.1145/2339530.2339693

43. Haley MacLeod, Kim Oakes, Danika Geisler, Kay Connelly, and Katie Siek. 2015. Rare World: Towards Technology for Rare Diseases. In Proceedings of the 33rd Annual ACM Conference on Human Factors in Computing Systems (CHI '15). ACM, New York, NY, USA, 1145-1154. http://dx.doi.org/10.1145/2702123.2702494

44. George E. Marcus. 1995. Ethnography in/of the World System: The Emergence of Multi-sited Ethnography. Annual Review of Anthropology 24: 95-117.

45. Claudia Müller, Dominik Hornung, Theodor Hamm, and Volker Wulf. 2015. Practice-based Design of a Neighborhood Portal: Focusing on Elderly Tenants in a City Quarter Living Lab. In Proceedings of the 33rd Annual ACM Conference on Human Factors in Computing Systems (CHI '15), ACM, New York, 22952304. http://dx.doi.org/10.1145/2702123.2702449

46. Claudia Müller, Lin Wan, and Dalibor Hrg. 2010. Dealing with wandering: a case study on caregivers' attitudes towards privacy and autonomy when reflecting the use of LBS. In Proceedings of the 16th ACM international conference on Supporting group work (GROUP '10), ACM, New York, 75-84. http://dx.doi.org/10.1145/1880071.1880082

47. René F. Navarro and Jesús Favela. 2011. Usability Assessment of a Pervasive System to Assist Caregivers in Dealing with Repetitive Behaviors of Patients with Dementia.In Proceedings of the 4th International Conference on PErvasive Technologies Related to Assistive Environments (PETRA '11). ACM, New York, 28:1-28:8. http://doi.org/10.1145/2141622.2141656

48. Corinna Ogonowski, Benedikt Ley, Jan Hess, Lin Wan, and Volker Wulf. 2013. Designing for the Living Room : Long-Term User Involvement in a Living Lab. In Proceedings of the 31st Annual ACM Conference on Human Factors in Computing Systems (CHI '13), ACM, New York, 1539-1548. http://doi.acm.org/10.1145/2470654.2466205

49. Marta E. Pagán-Ortiza, Dharma E. Cortés, Noelle Rudloff, Patricia Weitzman and Sue Levkoff. 2014. Use of an online community to provide support to caregivers of people with dementia. Journal of gerontological social work 57, 6-7: 694-709. http://dx.doi.org/10.1080/01634372.2014.901998

50. Sun Young Park and Yunan Chen. 2015. Individual and Social Recognition: Challenges and Opportunities in Migraine Management. In Proceedings of the 18th ACM Conference on Computer Supported Cooperative Work \& Social Computing (CSCW '15). ACM, New York, NY, USA, 1540-1551. http://dx.doi.org/10.1145/2675133.2675248

51. Ulrike Pfeil. 2007. Online social support for older people. SIGACCESS Access. Comput. 88: 3-8. http://dx.doi.org/10.1145/1278234.1278235

52. Ulrike Pfeil and Panayiotis Zaphiris. 2007. Patterns of empathy in online communication. In Proceedings of the SIGCHI Conference on Human Factors in Computing Systems (CHI '07). ACM, New York, NY, USA, 919-928. http://dx.doi.org/10.1145/1240624.1240763

53. Martin Pinquart and Sylvia Sörensen (2007). Correlates of physical health of informal caregivers: A metaanalysis. J Gerontol B Psychol Sci Soc Sci, 62, 2: 126137.

54. Eduardo Quintana and Jesus Favela. 2012. Augmented reality annotations to assist persons with Alzheimers and their caregivers. Personal and Ubiquitous Computing 17, 6: 1105-1116. http://dx.doi.org/10.1007/s00779-012-0558-6

55. Monika Riedel and Markus Kraus. 2011. Informal care provision in Europe: regulation and profile of providers. Centre for European Policy Studies.

56. Rose M. Rubin and Shelley I. White-Means. 2009. Informal caregiving: Dilemmas of sandwiched 
caregivers. Journal of Family and Economic Issues, 30, 3: 252-267. http://dx.doi.org/10.1007/s10834-0099155-x

57. Dirk Sauerland, Ansgar Wübker, Sandra M. G. Zwakhalen, et al. 2014. Costs of Care for People with Dementia Just Before and After Nursing Home Placement. Primary Data From Eight European Countries. In Proc. of 10th World Congress on Health Economies in the Age of Longevity, Dublin, Ireland.

58. Susanne Schinkinger and Hilda Tellioğlu. 2014. Design Implications to Systems Supporting Informal Caregivers' Daily Life. In Human-Computer Interaction. Applications and Services. Springer International Publishing, 341-350. http://dx.doi.org/10.1007/978-3-319-07227-2_33

59. Marén Schorch, Lin Wan, David Randall and Volker Wulf. 2016. Designing for Those who are Overlooked. Insider Perspectives on Care Practices and Cooperative Work of Elderly Informal Caregivers. In Proceedings of the 19th ACM Conference on Computer-Supported Cooperative Work and Social Computing (CSCW '16). ACM, New York, NY, USA, (to be published).

60. Meredith M. Skeels, Kenton T. Unruh, Christopher Powell, and Wanda Pratt. 2010. Catalyzing social support for breast cancer patients. In Proceedings of the SIGCHI Conference on Human Factors in Computing Systems (CHI '10). ACM, New York, NY, USA, 173182. http://dx.doi.org/10.1145/1753326.1753353

61. Laurie S. Stenberg-Nichols and Virginia W. Junk. 1997. The Sandwich Generation: Dependency, proximity and task assistance needs of parents. Journal of Family and Economic Issues 18, 3: 299-326. http://dx.doi.org/10.1023/A:1024978930126

62. Alexandra Stiver, Leonor Barroca, Marian Petre, Mike Richards, and Dave Roberts. 2015. Civic crowdfunding: how do offline communities engage online?. In Proceedings of the 2015 British HCI Conference (British HCI '15). ACM, New York, NY, USA, 37-45. http://doi.org/10.1145/2783446.2783585

63. Anselm Strauss and Juliet Corbin. 1998. Basics of qualitative research: Techniques and procedures for developing grounded theory. Sage publications, London.

64. Peggy A. Thoits. 1986. Social support as coping assistance. Journal of Consulting and Clinical Psychology 54, 4: 416-423. http://dx.doi.org/10.1037/0022-006X.54.4.416

65. Philippe Thomas, Fabrice Lalloué, Pierre-Marie Preux, et al. 2006. Dementia patients caregivers quality of life: the PIXEL study. International journal of geriatric psychiatry 21, 1: 50-56.

66. Matthieu Tixier, Gérald Gaglio, and Myriam Lewkowicz. 2009. Translating social support practices into online services for family caregivers. In Proceedings of the ACM 2009 international conference on Supporting group work (GROUP '09). ACM, New York, NY, USA, 71-80.

http://doi.acm.org/10.1145/1531674.1531685

67. Matthieu Tixier and Myriam Lewkowicz. 2015. Looking for Respite and Support: Technological Opportunities for Spousal Caregivers. In Proceedings of the 33rd Annual ACM Conference on Human Factors in Computing Systems (CHI '15). ACM, New York, NY, USA, 1155-1158. http://dx.doi.org/10.1145/2702123.2702563

68. Tarja K. Viitanen. 2007. Informal and formal care in Europe. IZA Discussion Paper No. 2648. Available at SSRN: http://ssrn.com/abstract $=970484$

69. Yi-Chia Wang, Robert Kraut, and John M. Levine. 2012. To stay or leave?: the relationship of emotional and informational support to commitment in online health support groups. In Proceedings of the ACM 2012 conference on Computer Supported Cooperative Work (CSCW '12). ACM, New York, NY, USA, 833842. http://dx.doi.org/10.1145/2145204.2145329

70. Marsha White and Steve M. Dorman. 2001. Receiving social support online: Implications for health education. Health Education Research 16, 6: 693-707. http://dx.doi.org/10.1093/her/16.6.693

71. Kevin B. Wright. 1999. The communication of social support within an on-line community for older adults: A qualitative analysis of the SeniorNet community. Communication Quarterly 47, 4: 33-43.

72. Bo Xie. 2008. Multimodal Computer-Mediated Communication and Social Support among Older Chinese Internet Users. Journal of Computer-Mediated Communication 13, 3: 751-767.

73. Naomi Yamashita, Hideaki Kuzuoka, Keiji Hirata, and Takashi Kudo. 2013. Understanding the conflicting demands of family caregivers caring for depressed family members. In Proceedings of the SIGCHI Conference on Human Factors in Computing Systems (CHI '13), ACM, New York, 2637-2646. http://dx.doi.org/10.1145/2470654.2481365

74. Panayiotis Zaphiris and Rifaht Sarwar. 2006. Trends, similarities, and differences in the usage of teen and senior public online newsgroups. ACM Trans.

Comput.-Hum. Interact. 13, 3: 403-422. http://dx.doi.org/10.1145/1183456.1183461

75. Chao Zhou, Aurélien Bénel, and Jean-Pierre Cahier. 2010. Beyond Web 2.0... And Beyond the Semantic Web. In From CSCW to Web 2.0: European Developments in Collaborative Design, Dave Randall and Pascal Salembier (eds.). Springer, London, 155171. http://dx.doi.org/10.1007/978-1-84882-965-7_8 